\title{
An Investigation of Antibacterial Resistance Patterns in Isolated Bacteria from Contaminated Water Samples in Poultry Slaughterhouses
}

\author{
Hadis Tavafi ${ }^{\mathrm{a}}$ \\ aBiology Department, Faculty of Science, Malayer University, Malayer. Iran. Email: $\underline{\text { h.tavafi@malayeru.ac.ir }}$ \\ (C) The Author 2020
}

\begin{abstract}
Nowadays, in the poultry industry, antibiotics are used to treat, prevent, and enhance poultry growth and production efficiency. Their irregular consumption has resulted in the spread of antibiotic-resistant bacteria in this industry. Antibiotic-resistant bacteria in contaminated waters can be transmitted into soil. The purpose of this study was to investigate the antibiotic resistance pattern of bacteria isolated from the water of chicken slaughterhouses around Hamadan (Iran) province. In this study, 20 water samples were collected from four slaughterhouses in Hamadan province (during spring and summer 2019). Initial isolation and identification of the bacteria were performed by pour plate culture and biochemical tests. The disc diffusion method was applied to investigate the resistance pattern. This study presents 109 screened isolates. Of these, 57.8\% E.coli, 35.7\% Salmonella spp., and $6.42 \%$ Klebsiella spp. were detected. Antibiograms of isolates showed that in E.coli, $23.09 \%$ were resistant to four types of the antibiotic tetracycline, amoxicillin, gentamicin, and chloramphenicol, $76.19 \%$ had only one type of antibiotic. Antibiotics for Salmonella spp. showed that $35.9 \%$ were resistant to tetracycline, gentamicin, and chloramphenicol, $64.10 \%$ to only one type of antibiotic. Also, in Klebsiella spp., $85.71 \%$ were sensitive to antibiotics, and only $14.28 \%$ were resistant to tetracycline. Conclusion: The results showed that the rate of multiple antibiotic resistance is relatively high, and contaminated water has a high potential for soil contamination. Therefore, resistant bacteria become more stable in the environment, and the health of the environment will be endangered. Therefore, it is necessary to study the antimicrobial resistance patterns of bacteria to study and maintain the health of the environment.
\end{abstract}

ARTICLE HISTORY

Received 24 May 2020

Revised 3 June 2020

Accepted 8 June 2020

\section{KEYWORDS}

Antibiogram

Resistant Bacteria

Slaughterhouse

Water

\section{Introduction}

Today, in human societies, poultry and poultry farming are considered an essential industry to provide the protein sources needed by the human population. In the poultry industry, antibiotics are used to treat, prevent, and increase the efficiency of poultry growth and production (use in the diet) (Donoghue, 2003). The use of antibiotics in this industry has caused increasing concern among consumers due to the creation of drug residues in food products (Ferguson et al., 2005). In recent decades, the rising use of antibiotics has led to the spread of resistant genes, resulting in increased antibiotic resistance of bacteria, which has led to a 
reduction in the effectiveness of drugs (Johnson et al., 2005). Antibiotic-resistant bacteria have become widespread due to the overuse of antibiotics. One of the issues considered a severe threat to the industry is bacterial disease. Losses, growth reduction, production reduction, the removal of carcasses from the environment, and the high cost of treatment are among the significant damage to the poultry industry due to bacterial diseases (Joseph et al., 2001). The high rate of presence of some resistant bacteria such as $E$. coli in contaminated water and soil has been linked to this industry as a result of reduced antibiotic efficacy in resistant bacteria (Khan et al., 2014). Bacterial contaminations are spread in different ways, including through contaminated water in the environment (especially in the soil) and can contaminate both humans and poultry. It is estimated that in the USA, approximately $50 \%$ of antibiotics given to animals are without the presence of disease, and the damage caused by improper and inappropriate use of antibiotics is sometimes higher than the damage caused by the disease itself (Van den Bogaard et al., 2001).

Recent studies have reported the emergence of multiple resistance patterns and an increase in the number of resistant bacteria (Wajid et al., 2019). Among resistant bacteria, the Enterobacteriaceae family showed the highest rate of antibiotic resistance. E. coli, and Salmonella spp. have the highest frequency. $E$. coli often causes gastrointestinal infections in humans and mammals, and in domestic birds, it causes widespread or local nongastrointestinal infections such as airway infection, Septicemia, and colibacillosis (Álvarez-Fernández et al., 2012).

Due to the prevalence of resistant bacteria in human societies, antibiotic resistance is of particular importance in terms of public health. This study aimed to investigate the antibiotic resistance patterns of contaminant bacteria of poultry slaughterhouses. Control and identification of the source of contamination in the spread of resistant bacteria is one way to deal with this problem. Due to the uncontrolled use of antibiotics in the poultry industry, and due to the recycling and use of poultry in the community, the transmission of resistant bacteria to the environment and humans is done. Slaughterhouses are one of the centers that easily allow this type of bacteria to enter the environment through drinking water. Water is one of the most critical pollutants due to its fluidity. Water easily contaminates soil and air and stabilizes pollution circulation in the ecosystem. Therefore, it is vital to study water pollution and prevent the spread of contamination with appropriate solutions. Thus, in this study, the antibiogram test is valuable to identify the patterns of antibiotic resistance and to prescribe and use antibiotics correctly.

\section{Materials and Methods}

\section{Sample collection}

To collect water samples, according to sampling standards, these were taken during spring and summer 2019 from the water of the consumption sections of four slaughterhouses in Hamadan Province (Iran). The physical and chemical specifications of the water sample are listed in Table 1. After sample collection, samples were transferred to the laboratory and glycerol stock of isolates stored at a $4^{\circ} \mathrm{C}$ for further investigation.

\section{Microbial culture and screening of bacterial isolates}

To screen isolates, Nutrient Agar (Merk, Germany) culture medium was used. Thus, $20 \mathrm{ml}$ of autoclaved culture medium, reduced to a temperature of $60^{\circ} \mathrm{C}$, was poured into sterile Petri dishes, and then $1 \mathrm{ml}$ of each of the water samples was added to the culture medium. Bacterial cultures were cultured using Pour Plate and incubated at $37^{\circ} \mathrm{C}$ for $24 \mathrm{~h}$. The pure culture was provided from each of the existing colonies.

\section{Biochemical and microbial identification of bacterial isolates}

Macroscopic properties (shape and size of colonies) and microscopic properties (Gram staining) were used to identify isolates. Biochemical tests including MRVP (Merk, Germany), TSI (Merk, Germany), SIM (Merk, Germany), Bailey Scoline (Merk, Germany), citrate, and culture on McConkey (Merk, Germany), EMB (Merk, Germany), Salmonella-Shigella (Merk, Germany), and Blood Agar, as well as nitrate reduction tests, were performed.

\section{Antibacterial test by Kirby Bauer method}

In order to determine the sensitivity and antibiotic resistance of screened isolates we used five highconsumption antibiotics common to Iran's poultry industry. The Disc diffusion test was performed on the Kirby Bauer method. In this study, was used tetracycline (30 micrograms), amoxicillin (10 micrograms), erythromycin (15 micrograms), gentamicin (10 micrograms) and chloramphenicol (30 micrograms). Antibiograms were performed according to the CLSI M100-S29 standard (CLSI, 2019). Briefly, bacteria inoculated in the of Muller-Hinton broth $(0.5$ 
McFarland $1.5 \times 10^{8} \mathrm{CFU}$ ) were cultured on the surface of Muller-Hinton Agar. Antibiotic discs were placed at regular intervals on the inoculated culture medium and incubated for 24 hours at $37^{\circ} \mathrm{C} A=\pi r^{2}$. After incubation, we used a metric ruler to measure the diameter of the zone of inhibition for each antibiotic used. Finally, the resistance and sensitivity of each isolate were compared with the global CLSI standard (CLSI, 2019).

Table 1. The physical and chemical characteristics of the water samples $\left(25^{\circ} \mathrm{C}\right.$ temperature).

\begin{tabular}{|l|l|l|l|l|l|}
\hline Test type & Unit & Slaughterhouse 1 & Slaughterhouse 2 & Slaughterhouse 3 & Slaughterhouse 4 \\
\hline $\mathrm{pH}$ & & 8.0 & 7.8 & 8.0 & 8.0 \\
\hline COD & $\mathrm{mg} / \mathrm{l}$ & 924 & 924 & 918 & 922 \\
\hline BOD & $\mathrm{mg} / \mathrm{l}$ & 451 & 452 & 455 & 451 \\
\hline DO & $\mathrm{mg} / \mathrm{l}$ & 2.1 & 2.0 & 2.2 & 2.1 \\
\hline Phosphate & $\mathrm{mg} / \mathrm{l}$ & 33.2 & 33.0 & 33.0 & 33.4 \\
\hline Nitrate & $\mathrm{mg} / \mathrm{l}$ & 83.4 & 83.0 & 82.8 & 83.2 \\
\hline Chloride & $\mathrm{mg} / \mathrm{l}$ & 439 & 430 & 417 & 433 \\
\hline Sulfate & $\mathrm{mg} / \mathrm{l}$ & 150 & 150 & 146 & 155 \\
\hline Ammonium & $\mathrm{mg} / \mathrm{l}$ & 60.2 & 59.8 & 60 & 60.7 \\
\hline TSS & $\mathrm{mg} / \mathrm{l}$ & 284 & 301 & 296 & 279 \\
\hline TDS & $\mathrm{mg} / \mathrm{l}$ & 2040 & 2040 & 2043 & 2036 \\
\hline Turbidity & $\mathrm{NTU}$ & 397 & 397 & 397 & $\sim 396$ \\
\hline Sulfite & $\mathrm{mg} / \mathrm{l}$ & 0.9 & 0.89 & 0.75 & 0.92 \\
\hline Sulfide & $\mathrm{mg} / \mathrm{l}$ & 1.1 & 0.98 & 1.25 & 1.0 \\
\hline
\end{tabular}

\section{Statistical analysis}

The obtained data were analyzed using the SPSS 26 version and Chi-square test at a significance level of $\mathrm{p}$ $\leq 0.05$.

\section{Results and Discussion}

In this study, 109 bacterial isolates were isolated. According to the present results, were reported that 63 cases $(57.8 \%)$ of E.coli, 39 cases $(35.7 \%)$ of Salmonella spp., and 7 cases (6.42\%) of Klebsiella spp. Balakrishnan et al. (2018) studied the prevalence of Salmonella spp., in chicken meat and its slaughtering place from local markets in Orathanadu. A prevalence of $33.3 \%(5 / 15)$ and $60 \%(3 / 5)$ Salmonella was observed from chicken meat and water samples, respectively. (Balakrishnan et al., 2018).

Antibiogram test of isolates showed that in isolated $E$. coli, $76.19 \%$ (48 cases) resisted only one type of antibiotic and $23.09 \%$ (15 cases) resisted 2, 3, 4, or 5 antibiotics. The results of the discs diffusion test in $E$. coli showed in Tables 2 and 3, respectively. The chisquare test showed that the difference in the resistance and sensitivity of the isolates to the studied drugs was significant $(\mathrm{p} \leq 0.05)$. The highest antibiotic resistance was observed against tetracycline. The highest and lowest frequency of the multi-antibiotic resistance of the isolates was $46.03 \%$ and $12.7 \%$, respectively, which was significant statistically (Table 3 ). Seifi et al. (2015) examined antibiotic sensitivity and resistance of isolated E.coli in Mazandaran (Iran). They reported to the highest percentage of resistance to tetracycline $(71.25 \%)$, erythromycin $(65 \%)$, ampicillin $(62.5 \%)$, fluoxetine (7.5\%) and Florfenicol (7.5\%), respectively. (Seifi et al., 2015).

Table 2. Resistance frequency of 63 isolated E. coli relative to only one type of antibiotic.

\begin{tabular}{|l|l|l|l|}
\hline & Antibiotics & $\begin{array}{l}\text { Resistant } \\
(\mathbf{\%})\end{array}$ & $\begin{array}{l}\text { Sensitive } \\
(\mathbf{\%})\end{array}$ \\
\hline 1 & Tetracycline & $62(98.41 \%)$ & $1(1.59 \%)$ \\
\hline 2 & Amoxicillin & $55(87.30 \%)$ & $8(12.7 \%)$ \\
\hline 3 & Erythromycin & $59(93.65 \%)$ & $4(6.35 \%)$ \\
\hline 4 & Gentamicin & $47(74.60 \%)$ & $16(25.40 \%)$ \\
\hline 5 & Chloramphenicol & $46(73.01 \%)$ & $17(26.99 \%)$ \\
\hline
\end{tabular}

Salmonella spp. Antibiogram test showed that $64.10 \%$ (25 cases) resisted only one type of antibiotic (Table 4), 35.9\% (14 cases) resisted tetracycline, gentamicin, and chloramphenicol (Table 5). Among the 4 antibiotic resistance patterns, $25.64 \%$ of the isolates were the common pattern of number $1,12.82 \%$ of the isolates were in the common pattern of number $2,5.12 \%$ of the isolates were in the common pattern of number 3 and $56.41 \%$ of the isolates were in the common pattern of number 4 . The highest and lowest frequencies of the multi-antibiotic resistance of the isolates were $56.41 \%$ and $5.12 \%$, respectively, which was significant statistically ( $\mathrm{p} \leq 0.05)$. Shang et al. (2019) investigated the distribution, antimicrobial susceptibility patterns, serotypes, and genotypes of Salmonella spp. isolates from a slaughterhouse. Their results indicated that the highest antimicrobial resistance rate was against 
nalidixic acid $(92.7 \%)$, that $56.7 \%$ isolates were multidrug-resistant (MDR), and that the resistance profile of $20.7 \%$ isolates was relative to ampicillin, chloramphenicol, streptomycin, sulfonamides, and tetracycline (Shang et al., 2019).

Table 3. Multi-Antibiotic resistance patterns of 63 isolated E. coli relative to studied antibiotics.

\begin{tabular}{|l|l|l|l|}
\hline $\begin{array}{l}\text { Num. of } \\
\text { patterns }\end{array}$ & $\begin{array}{l}\text { Num. of } \\
\text { Antibiotics }\end{array}$ & $\begin{array}{l}\text { Resistance to } \\
\text { antibiotics }\end{array}$ & $\begin{array}{l}\text { Num. of } \\
\text { isolated } \boldsymbol{E} . \\
\text { coli }\end{array}$ \\
\hline 1 & 2 & TE- E & $8(12.7 \%)$ \\
\hline 2 & 3 & TE- Gen- AMX & $13(20.63 \%)$ \\
\hline 3 & 4 & TE- Chl- Gen- E & $29(46.03 \%)$ \\
\hline 4 & 5 & $\begin{array}{l}\text { TE- Chl- Gen- E- } \\
\text { AMX }\end{array}$ & $13(20.63 \%)$ \\
\hline
\end{tabular}

Note: AMX: Amoxicillin; TE: Tetracycline; E: Erythromycin; Gen: Gentamicin; Chl: Chloramphenicol.

Also, in the case of Klebsiella spp., $85.71 \%$ were sensitive to amoxicillin, erythromycin, gentamicin, and chloramphenicol antibiotics, and only $14.28 \%$ were resistant to tetracycline. The results showed that among these isolates, also were observed cases with multiple resistances. Savin et al. (2020) reported that wastewater effluents from the poultry slaughterhouses exhibited clinically relevant bacteria (E. coli $(39.4 \%)$, methicillin-resistant S.aureus (12.3\%), K. pneumonia (10.8\%), and species of the ACB (32.4\%), which were widely distributed in their wastewater effluents (Savin et al., 2020).

The results showed that tetracycline resistance was present in screened isolates in this study. Tetracycline is one of the common antibiotics used as a dietary supplement and antibiotic in the poultry industry. Due to the excessive use of tetracycline, an increase in the appearance of resistant strains of this antibiotic is expected (Donoghue, 2003).

In this study, samples of water contaminated with $E$. coli, salmonella spp., and Klebsiella spp. have strains that show multiple antibiotic resistances, which pose a serious threat to the environment. Zhu et al. (2017) reported antimicrobial susceptibility profiles of The Salmonella isolates to 10 categories of antimicrobial agents using the Kirby-Bauer disc diffusion Method that were observed: nalidixic acid (99.5\%), ampicillin $(87.8 \%)$, tetracycline $(51.9 \%)$, ciprofloxacin $(48.7 \%)$, trimethoprim/ sulfamethoxazole (48.1\%), and spectinomycin (34.4\%). Antimicrobial resistance profiling showed that $60.8 \%$ of isolates were multidrug-resistant (MDR), and MDR strains increased from $44.7 \%$ to $78.6 \%$ along the slaughtering line (Zhu et al., 2017).

Table 4. Resistance frequency of 39 isolated Salmonella spp. relative to only one type of antibiotic.

\begin{tabular}{|l|l|l|l|}
\hline & Antibiotics & Resistant (\%) & Sensitive (\%) \\
\hline 1 & Tetracycline & $31(79.48 \%)$ & $8(20.52 \%)$ \\
\hline 2 & Amoxicillin & $17(43.58 \%)$ & $22(56.42 \%)$ \\
\hline 3 & Erythromycin & $14(35.90 \%)$ & $25(64.1 \%)$ \\
\hline 4 & Gentamicin & $9(23.07 \%)$ & $30(76.93 \%)$ \\
\hline 5 & Chloramphenicol & $28(71.8 \%)$ & $11(28.2 \%)$ \\
\hline
\end{tabular}

Table 5. Multi-Antibiotic resistance patterns of 39 isolated Salmonella spp. relative to studied antibiotics.

\begin{tabular}{|l|l|l|l|}
\hline $\begin{array}{l}\text { Num. of } \\
\text { patterns }\end{array}$ & $\begin{array}{l}\text { Num. of } \\
\text { Antibiotics }\end{array}$ & $\begin{array}{l}\text { Resistance to } \\
\text { antibiotics }\end{array}$ & $\begin{array}{l}\text { Num. of isolated } \\
\text { Salmonella } \text { spp. }\end{array}$ \\
\hline 1 & 2 & TE- Chl & $10(25.64 \%)$ \\
\hline 2 & 2 & TE- Gen & $5(12.82 \%)$ \\
\hline 3 & 2 & Chl- Gen & $2(5.12 \%)$ \\
\hline 4 & 3 & TE- Chl- Gen & $22(56.41 \%)$ \\
\hline
\end{tabular}

Note: TE: Tetracycline; Gen: Gentamicin; Chl: Chloramphenicol.

\section{Conclusions}

Results show a high rate of multiple antibiotic resistance was observed in screened isolates. In slaughterhouses, because water is used to slaughter and wash carcasses, and the water is in direct contact with poultry, their pollution is high, and unfortunately, there is not enough management to control the outflow water, so the transfer of isolates to the environment outside the slaughterhouse occurs, and water can transmit these contaminants to the environment (especially soil) and make resistant bacteria more stable in the environment, thus endangering the health of the environment. Therefore, it is necessary to study the antibiotic resistance profiles of bacteria to monitor for antibacterial resistance and proper use of antibiotics in slaughterhouses, and it is also essential to preserve the health of the environment.

\section{Acknowledgment}

This project was funded by Malayer University, Malayer, Iran. The author thanks the biology department of Malayer University.

\section{Conflict of interest}

The author declares that she has no conflict of interest.

\section{References}

Álvarez-Fernández, E., Alonso-Calleja, C., GarcíaFernández, C., \& Capita, R. (2012). Prevalence and antimicrobial resistance of Salmonella serotypes isolated from poultry in Spain: comparison between 1993 and 2006. International Journal of Food Microbiology, 153(3), 281-287. https://doi.org/10.1016/j.ijfoodmicro.2011.1 $\underline{1.011}$ 
Balakrishnan, S., Sangeetha, A., \& Dhanalakshmi, M. (2018). Prevalence of Salmonella in chicken meat and its slaughtering place from local markets in Orathanadu, Thanjavur district, Tamil Nadu. Journal of Entomology and Zoology Studies, 6(2), 2468-2247.

CLSI. (2019). Performance standards for antimicrobial susceptibility testing; twentyninth informational supplement. CLSI document M100-S29. Clinical and Laboratory Standards Institute, Wayne, PA.

Donoghue, D. J. (2003). Antibiotic residues in poultry tissues and eggs: human health concerns? Poultry Science, 82(4), 618-621. https://doi.org/10.1093/ps/82.4.618

Ferguson, J., Baxter, A., Young, P., Kennedy, G., Elliott, C., Weigel, S., . . . Sharman, M. (2005). Detection of chloramphenicol and chloramphenicol glucuronide residues in poultry muscle, honey, prawn and milk using a surface plasmon resonance biosensor and Qflex ${ }^{\circledR}$ kit chloramphenicol. Analytica Chimica Acta, 529(1-2), 109-113. https://doi.org/10.1016/j.aca.2004.11.042

Johnson, J. R., Kuskowski, M. A., Smith, K., O’Bryan, T. T., \& Tatini, S. (2005). Antimicrobialresistant and extraintestinal pathogenic Escherichia coli in retail foods. The Journal of Infectious Diseases, 191(7), 1040-1049. https://doi.org/10.1086/428451

Joseph, S., Hayes, J., English, L., Carr, L., \& Wagner, D. (2001). Implications of multiple antimicrobial-resistant enterococci associated with the poultry environment. Food Additives \& Contaminants, 18(12), 1118-1123. https://doi.org/10.1080/02652030110051275

Khan, M., Akhtar, N., Haque, M., Barua, A., Chowdhury, T., \& Mullick, R. (2014). Isolation and identification of nonplasmid multidrug resistant E. coli from poultry wastes in Chittagong region. Bangladesh. Journal of Bacteriology and Parasitology, 5(1), 1-7. http://dx.doi.org/10.4172/21559597.1000182

Savin, M., Bierbaum, G., Hammerl, J. A., Heinemann, C., Parcina, M., Sib, E., . . . Kreyenschmidt,
J. (2020). ESKAPE bacteria and extendedspectrum- $\beta$-lactamase-producing Escherichia coli isolated from wastewater and process water from German poultry slaughterhouses. Applied and Environmental Microbiology, 86(8).

http://dx.doi.org/10.1128/AEM.02748-19

Seifi, S., Khoshbakht, R., \& Atabak, A. (2015). Antibiotic susceptibility, serotyping and pathogenicity evaluation of avian Escherichia coli isolated from broilers in northern Iran. Bulgarian Journal of Veterinary Medicine, 18(2). https://dx.doi.org/10.15547/bjvm.819

Shang, K., Wei, B., Jang, H.-K., \& Kang, M. (2019). Phenotypic characteristics and genotypic correlation of antimicrobial resistant (AMR) Salmonella isolates from a poultry slaughterhouse and its downstream retail markets. Food Control, 100, 35-45. https://doi.org/10.1016/j.foodcont.2018.12.0 $\underline{46}$

van den Bogaard, A., London, N., Driessen, C., \& Stobberingh, E. (2001). Antibiotic resistance of faecal Escherichia coli in poultry, poultry farmers and poultry slaughterers. Journal of Antimicrobial Chemotherapy, 47(6), 763771. https://doi.org/10.1093/jac/47.6.763

Wajid, M., Saleemi, M. K., Sarwar, Y., \& Ali, A. (2019). Detection and characterization of multidrug-resistant Salmonella enterica serovar Infantis as an emerging threat in poultry farms of Faisalabad, Pakistan. Journal of Applied Microbiology, 127(1), 248-261.

https://dx.doi.org/10.1016/j.theriogenology.2 $\underline{019.08 .034}$

Zhu, Y., Lai, H., Zou, L., Yin, S., Wang, C., Han, X., . .. Zhou, K. (2017). Antimicrobial resistance and resistance genes in Salmonella strains isolated from broiler chickens along the slaughtering process in China. International Journal of Food Microbiology, 259, 43-51. https://doi.org/10.1016/j.ijfoodmicro.2017.0 $\underline{7.023}$ 
Publisher's note: Eurasia Academic Publishing remains neutral with regard to jurisdictional claims in published maps and institutional affiliations.

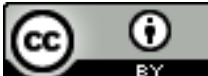

Open Access This article is licensed under a Creative Commons Attribution-NoDerivatives 4.0 International (CC BY-ND 4.0) licence, which permits copy and redistribute the material in any medium or format for any purpose, even commercially. The licensor cannot revoke these freedoms as long as you follow the licence terms. Under the following terms you must give appropriate credit, provide a link to the license, and indicate if changes were made. You may do so in any reasonable manner, but not in any way that suggests the licensor endorsed you or your use. If you remix, transform, or build upon the material, you may not distribute the modified material.

To view a copy of this license, visit https://creativecommons.org/licenses/by-nd/4.0/. 